University of Nebraska - Lincoln

DigitalCommons@University of Nebraska - Lincoln

USDA Wildlife Services - Staff Publications

U.S. Department of Agriculture: Animal and Plant Health Inspection Service

2016

\title{
Effects of simulated removal activities on movements and space use of feral swine
}

Justin W. Fischer

USDA/APHIS/WS National Wildlife Research Center, Justin.w.fischer@aphis.usda.gov

Dan McMurty

United States Department of Agriculture, Animal and Plant Health Inspection Service, Wildlife Services

Chad R. Blass

United States Department of Agriculture, National Wildlife Research Center

W. David Walter

Pennsylvania State University

Jeff Beringer

Missouri Department of Conservation

See next page for additional authors

Follow this and additional works at: https://digitalcommons.unl.edu/icwdm_usdanwrc

Part of the Life Sciences Commons

Fischer, Justin W.; McMurty, Dan; Blass, Chad R.; Walter, W. David; Beringer, Jeff; and Vercauteren, Kurt C., "Effects of simulated removal activities on movements and space use of feral swine" (2016). USDA Wildlife Services - Staff Publications. 1843.

https://digitalcommons.unl.edu/icwdm_usdanwrc/1843

This Article is brought to you for free and open access by the U.S. Department of Agriculture: Animal and Plant Health Inspection Service at DigitalCommons@University of Nebraska - Lincoln. It has been accepted for inclusion in USDA Wildlife Services - Staff Publications by an authorized administrator of DigitalCommons@University of Nebraska - Lincoln. 


\section{Authors}

Justin W. Fischer, Dan McMurty, Chad R. Blass, W. David Walter, Jeff Beringer, and Kurt C. Vercauteren 


\title{
Effects of simulated removal activities on movements and space use of feral swine
}

\author{
Justin W. Fischer ${ }^{1}$ - Dan McMurtry ${ }^{2}$ - Chad R. Blass ${ }^{1}$ - W. David Walter ${ }^{3}$. \\ Jeff Beringer $^{4} \cdot$ Kurt C. VerCauteren ${ }^{1}$
}

Received: 9 February 2016 /Revised: 19 February 2016 / Accepted: 24 February 2016 / Published online: 28 March 2016

(C) Springer-Verlag Berlin Heidelberg (outside the USA) 2016

\begin{abstract}
Abundance and distribution of feral swine (Sus scrofa) in the USA have increased dramatically during the last 30 years. Effective measures are needed to control and eradicate feral swine populations without displacing animals over wider areas. Our objective was to investigate effects of repeated simulated removal activities on feral swine movements and space use. We analyzed location data from 21 feral swine that we fitted with Global Positioning System harnesses in southern MO, USA. Various removal activities were applied over time to eight feral swine before lethal removal, including trapped-and-released, chased with dogs, chased with hunter, and chased with helicopter. We found that core space-use areas were reduced following the first removal activity, whereas overall space-use areas and diurnal movement distances increased following the second removal activity. Mean geographic centroid shifts did not differ between pre- and postperiods for either the first or second removal activities. Our information on feral swine movements and space use precipitated by human removal activities, such as hunting, trapping,
\end{abstract}

Kurt C. VerCauteren

kurt.c.vercautern@aphis.usda.gov

1 United States Department of Agriculture, Animal and Plant Health Inspection Service, Wildlife Services, National Wildlife Research Center, 4101 LaPorte Avenue, Fort Collins, CO 80521-2154, USA

2 United States Department of Agriculture, Animal and Plant Health Inspection Service, Wildlife Services, 1714 Commerce Ct Suite C., Columbia, MO 65202, USA

3 US Geological Survey, Pennsylvania Cooperative Fish and Wildlife Research Unit, The Pennsylvania State University, 403 Forest Resources Building, University Park, PA 16802, USA

4 Missouri Department of Conservation, 1110 S. College Ave, Columbia, MO 65201, USA and chasing with dogs, helps fill a knowledge void and will aid wildlife managers. Strategies to optimize management are needed to reduce feral swine populations while preventing enlarged home ranges and displacing individuals, which could lead to increased disease transmission risk and human-feral swine conflict in adjacent areas.

Keywords Feral swine · Global Positioning System · Harassment $\cdot$ Home range $\cdot$ Missouri $\cdot$ Sus scrofa $\cdot$ Wild hogs

\section{Introduction}

Wild boar, which are native to Eurasia, and feral swine, which are found in the USA and can collectively be descendants of wild boar, escaped domestic swine, or hybrids of the two are highly invasive pest species throughout the world that negatively impact natural and man-made environments and pose a threat to animal and human health (Witmer et al. 2003; Seward et al. 2004; Mayer 2009). Currently, the feral swine population in the USA is estimated at over five million (Pimentel 2007), and they have been reported in at least 40 states. Costs associated with damage caused by feral swine are estimated to be $\$ 1.5$ billion annually (Pimentel 2007) and are increasing because feral swine populations and range continue to expand. Current removal measures for feral swine have not been universally successful, and more effective methods and strategies are needed.

Lethal strategies to remove feral swine differ considerably in efficacy and effort required. Trapping is the most common tool used to reduce feral swine densities (West et al. 2009) and has reduced populations by up to $83 \%$ in an area of Australia (Choquenot et al. 1993). A disadvantage to trapping is that many trap designs are big and heavy, which limits use to areas accessible by vehicles. Snares are highly portable and can be an effective removal tool (Anderson and Stone 1993; Hess 
et al. 2006), but nontarget species are at risk to capture. Recreational hunting of feral swine can be a source of revenue for landowners and state wildlife agencies (Chambers 1999; Kreith 2007; West et al. 2009), though often fails to consistently remove the desired number of individuals (Barrett and Stone 1993; Zivin et al. 2000; Massei et al. 2015) or the correct gender and age class (Bieber and Ruf 2005; Toigo et al. 2008; Keuling et al. 2013) needed to effectively reduce feral swine populations. Controlled shooting or professional sharpshooting have proven effective at quickly removing individual feral swine and entire sounders (Coblentz and Baber 1987; Hoffman 2009; West et al. 2009). Hunting with dogs has been used to reduce feral swine populations around the world (Katahira et al. 1993; Maillard and Fournier 1995; Parkes et al. 2010) and is a popular recreational activity in the USA (Dickson et al. 2003). Rapid eradication of feral swine can also be achieved through aerial shooting (Hone 1983; Choquenot et al. 1999; Parkes et al. 2010), although success is impacted by overstory vegetation types and ability to locate feral swine (West et al. 2009; Campbell et al. 2010; Massei et al. 2011).

The "Judas" hog technique, or using feral swine with very high frequency (VHF) or Global Positioning System (GPS) collars to locate other feral swine, has been used with some success to eradicate feral swine from islands, national parks, and fenced areas (Mcllroy and Gifford 1997; McCann and Garcelon 2008; Parkes et al. 2010). Although there are no toxicants currently registered by the US Environmental Protection Agency for use on feral swine in the USA, researchers in New Zealand have recently registered a bait matrix that includes sodium nitrite and is lethal to feral swine (Shapiro et al. 2015).

Limited research has been conducted in Europe and Australia on how removal measures affect feral swine space use and movement patterns. Using dogs to drive wild boar past standers with guns in France and Italy revealed a temporary increase in daytime resting area size and increases in movement that were related to degree of hunting pressure (Maillard and Fournier 1995; Scillitani et al. 2010). Conversely, Keuling et al. (2008) did not document a significant impact of hunting with dogs on wild boar home range size or location in northeastern Germany. Similarly, wild boar driven with dogs in northern Germany escaped without leaving their established home ranges (Sodeikat and Pohlmeyer 2003). Aerial shooting has also been determined to have little effect on space use and movement distances of feral swine in Australia (Dexter 1996) and the USA (Campbell et al. 2010).

There have been no research efforts devoted to understanding how multiple types of removal activities might affect feral swine behavior in North America (except, see Campbell et al. 2012). Our study goals were to determine if repeated simulated removal activities altered the size or location of space-use areas and assess differences in feral swine movements before, during, and after simulated removal activities. We hypothesized that removal activities would cause a temporary increase in diurnal movement distances and that space-use areas would increase in size after each removal activity. Increased movement away from harassment events and beyond previously established space-use areas could hinder eradication strategies and increase risk of range expansion and disease transmission.

\section{Methods}

\section{Study area}

We conducted our study in the following 13 counties in southern Missouri (from east to west): Mississippi, Dunklin, Wayne, Madison, Iron, Washington, Reynolds, Texas, Ozark, Taney, St. Clair, Vernon, and Bates. Our study sites occurred in three major ecoregions, the Ozark Highlands, Osage Plains, and Mississippi Lowlands regions. The Ozark Highlands consisted of densely forested areas with interspersed ridges, valleys, and pastures with minimal row crops. Overstory vegetation consisted of red and white oak (Quercus spp.), hickory (Carya spp.), and red cedar (Juniperus virginiana). The Osage Plains were mostly flat with some hills and small isolated forested areas along rivers and streams. Flat areas were dominated by agriculture, often consisting of row crops and cattle pastures. The Mississippi Lowlands consisted of row crops and traditional Mississippi Delta timber. These timbered areas included green ash (Fraxinus pennsylvanica), pin oak (Quercus palustris), overcup oak (Q. lyrata), and sweetgum (Liquidambar styraciflua).

Annual mean monthly temperature across study sites was $14{ }^{\circ} \mathrm{C}$ with a mean January low temperature in southeast Missouri of $1{ }^{\circ} \mathrm{C}$ and a mean July high of $27{ }^{\circ} \mathrm{C}$ (National Climatic Center; http://www.ncdc.noaa.gov). Mean annual precipitation in southern Missouri ranged from 109 to $126 \mathrm{~cm}$ (National Climatic Center; http://www.ncdc.noaa. gov). Study sites included a mix of private, US Forest Service, state conservation, and state park lands.

\section{Feral swine capture}

We captured male and female feral swine from April 2009 to April 2013 with rooter-door corral traps baited with dry and/or fermented whole kernel corn. We immobilized (Telazol ${ }^{\circledR}$ $1 \mathrm{mg} / 23 \mathrm{~kg}$ body weight) one adult per captured sounder, via dart gun, that was estimated to be $\geq 45 \mathrm{~kg}$ and placed a harness equipped with a GPS receiver (North Star Science and Technology, King George, VA) on the individual. The remaining captured feral swine were euthanized via gunshot in support of ongoing state and federal efforts to eradicate feral swine from Missouri. We recorded weight, gender, stomach 
content, chest girth, and pregnancy status of euthanized feral swine.

We programmed GPS harnesses to collect locations hourly, emit a VHF signal continuously, and upload three locations daily so real-time locations of harnessed swine were known. Harnesses were deployed on feral swine for $\leq 3$ months to prevent individuals from outgrowing the original harness fit. We recovered harnesses from hunter- and landownerharvested feral swine, harnesses that slipped off individuals, retrapping, and by locating feral swine via VHF receiver and euthanasia via gunshot.

\section{Simulated removal activities}

We conducted simulated removal activities year-round, and number of attempts and types applied varied per individual. Multiple removal activities were applied to feral swine, when possible, to measure effects of removal activities on space use and movements. Removal activities included trapped-and-released, chased with dogs, chased with hunter, and chased with helicopter. Similar to before, feral swine captured in traps in addition to harnessed individuals during trap-and-release removal activities were euthanized. The chased with dogs removal activity included dogs chasing and eventually catching harnessed feral swine and then releasing them. We simulated feral swine hunting by locating harnessed individuals using a VHF receiver, pursuing them until visually identified, and then shot at them with a firearm. We also located feral swine via helicopter and VHF receiver and then pursued harnessed individuals for 2-3 min. Our feral swine removal attempts were to simulate population reduction techniques, not actually remove harnessed individuals. We also harnessed a subset of feral swine and applied no removal activities with these individuals so they could serve as a control group.

\section{Space-use estimation}

We estimated space-use areas (i.e., utilization distributions (UDs)) from feral swine locations collected before and after removal activities to measure the impact these activities had on UD size. To decrease probability of incorporating locations that were related to our harnessing of individuals, we did not include GPS fixes in analyses until $24 \mathrm{~h}$ after harness attachment. We compared location data between 2-week periods before and after removal activities. Because control feral swine received no removal activities, we chose only one 2week period which included GPS fixes $\geq 1$ and $\leq 15$ days after harness attachment. We did not include feral swine fixes collected $\leq 24 \mathrm{~h}$ after removal activity initiation when estimating 2-week UDs but did use these locations to calculate daily distances traveled (see below). We used a movement-based kernel density estimator (MKDE) to estimate UDs, which used a biased random bridge approach, incorporated movement trajectories, and accounted for serial autocorrelation of relocations (Benhamou and Cornelis 2010; Benhamou 2011). To assume that feral swine were moving at a constant biased random walk during each step, we set the upper time limit for GPS fixes to be included in the MKDE analysis at $3 \mathrm{~h}$ and considered locations $<50 \mathrm{~m}$ apart to be inactive. Core (50\%) and overall (95\%) UD contours were computed in R (version 3.1.0, R Development Core Team 2013) using the adehabitatHR package (Calenge 2006).

We calculated and compared average $( \pm \mathrm{SE})$ core and overall UD size by 2-week pre- and post-removal periods for treatment feral swine and 2-week periods for control feral swine. To determine if core and overall UD areas changed in size following removal activities, we used a generalized linear mixed model (GLMM) to account for repeated measures, using the lme4 package (Bates et al. 2014). We only compared core and overall UD areas within a removal activity (pre- and post-activity), rather than across multiple removal activities, to remove bias associated with year and seasonal effects.

\section{Movement analysis}

Average $( \pm \mathrm{SE})$ and maximum daily distance traveled were estimated for each pre- and post-period, as well as a 24-h period directly after the removal activity was initiated. We calculated movement distances from straight line distances between sequential GPS locations. We also calculated mean geographic center (i.e., centroid) of GPS fixes, using ArcGIS (version 10.0; ESRI 2013), for feral swine by 2 -week pre- and post-removal periods to estimate shifts in activity. We used a GLMM to evaluate if centroid shifts differed significantly between the first and second removal activities.

We used a generalized linear model (GLM) to test if daily, nocturnal, or diurnal movement distances differed between the first 2-week pre-removal activity period for feral swine that received removal activities and 2 -week periods for control feral swine. We chose this first 2-week pre-removal activity period because this time period allowed us to make the best comparison between naive behaviors of treatment and control individuals (i.e., no prior removal activities to treatment individuals). We classified locations as diurnal or nocturnal by using a solar elevation angle of $0^{\circ}$. Daily, nocturnal, and diurnal movement distances were all based on a 24-h calendar day. Similar to our core and overall UD area analysis, we also used a GLMM to determine if movement distances changed following a removal activity for daily, nocturnal, or diurnal time periods for treatment individuals.

\section{Results}

From 2009 to 2013, approximately 1079 feral swine were trapped. Of those, we harnessed 31 (15 males and 16 females). 
We computed movement patterns and UD estimates for 21 of these due to GPS or harness failure, public hunting, and USDA/APHIS/Wildlife Services operational harvesting. We collected 18,132 feral swine GPS fixes from harnesses in which no removal activities were applied and 20,265 GPS fixes from harnesses on feral swine that experienced removal activities. Removal activities were applied to 8 feral swine, and 13 feral swine received no removal activities. Due to low sample sizes per treatment and control groups, we pooled all males, females, and removal activities into two removal activity groups (i.e., first and second) for all subsequent analyses.

We applied a combination of four removal activities to feral swine a maximum of 12 times throughout a calendar year (Fig. 1). Five feral swine received two removal activities that included a combination of our removal activity methods (Fig. 1). Three feral swine received a single removal activity, and those only included chased with a hunter. Average daily distances traveled for feral swine receiving the first removal activity was $2715 \pm 299 \mathrm{~m}$ for 2 -week periods before removal activities and $2661 \pm 288 \mathrm{~m}$ for 2 -week periods after removal activities (Table 1). Average daily distances traveled for 2week periods for feral swine receiving no removal activity was $2723 \pm 228 \mathrm{~m}$ (Table 1). Maximum hourly movements ranged from 562 to $3991 \mathrm{~m}$ for 2-week pre-and post-periods for feral swine receiving removal activities and from 830 to $4411 \mathrm{~m}$ for 2-week periods for feral swine receiving no removal activities. Mean distances traveled by feral swine during the first 24-h post-removal activity was greatest from 0:00 to $6: 00 \mathrm{~h}(1831 \pm 413 \mathrm{~m})$ and least during the second $24-\mathrm{h}$ post-removal activity from $18: 01$ to $24: 00(374 \pm 205 \mathrm{~m}$; Fig. 2).

Movement distances of treatment pigs did not differ significantly more than movement distances of control pigs for daily $(\beta=-8.09, p=0.983)$, nocturnal $(\beta=158.80, p=0.673)$, or diurnal $(\beta=-166.90$, $p=0.603)$ time periods. Daily, nocturnal, and diurnal movement distances did not differ significantly for 2week pre- and post-periods regarding the first removal activity $(\beta=-53.93, \mathrm{SE}=379.31 ; \beta=-147.10$, $\mathrm{SE}=233.70 ; \beta=93.14, \mathrm{SE}=149.64$; respectively) for treatment individuals. We did find an increase in daily movement distances of treatment pigs for 2-week preand post-periods regarding the second removal activity $(\beta=506.00, \mathrm{SE}=253.90)$ though, which can be attributed to higher diurnal movement distances $(\beta=183.53$, $\mathrm{SE}=77.42$ ). Nocturnal movement distances for preand post-periods for the second removal activity did not differ $(\beta=322.50, \mathrm{SE}=227.60)$.

Core UD areas were significantly reduced following the first removal activity $(\beta=-13.92, \mathrm{SE}=6.77$; Fig. 3$)$. However, overall UD areas were not different following the first removal activity $(\beta=-74.86, \mathrm{SE}=68.81$; Fig. 3). Following the second removal activity, core $\mathrm{UD}$ areas were not different $(\beta=8.54, \mathrm{SE}=10.89)$ while overall UD areas were higher $(\beta=97.14, \mathrm{SE}=16.99$; Fig. 3). Average centroid shifts between the first and second removal activities were 434 and $670 \mathrm{~m}$, respectively; however, these shifts were not significant $(\beta=235.40, \mathrm{SE}=140.77)$.

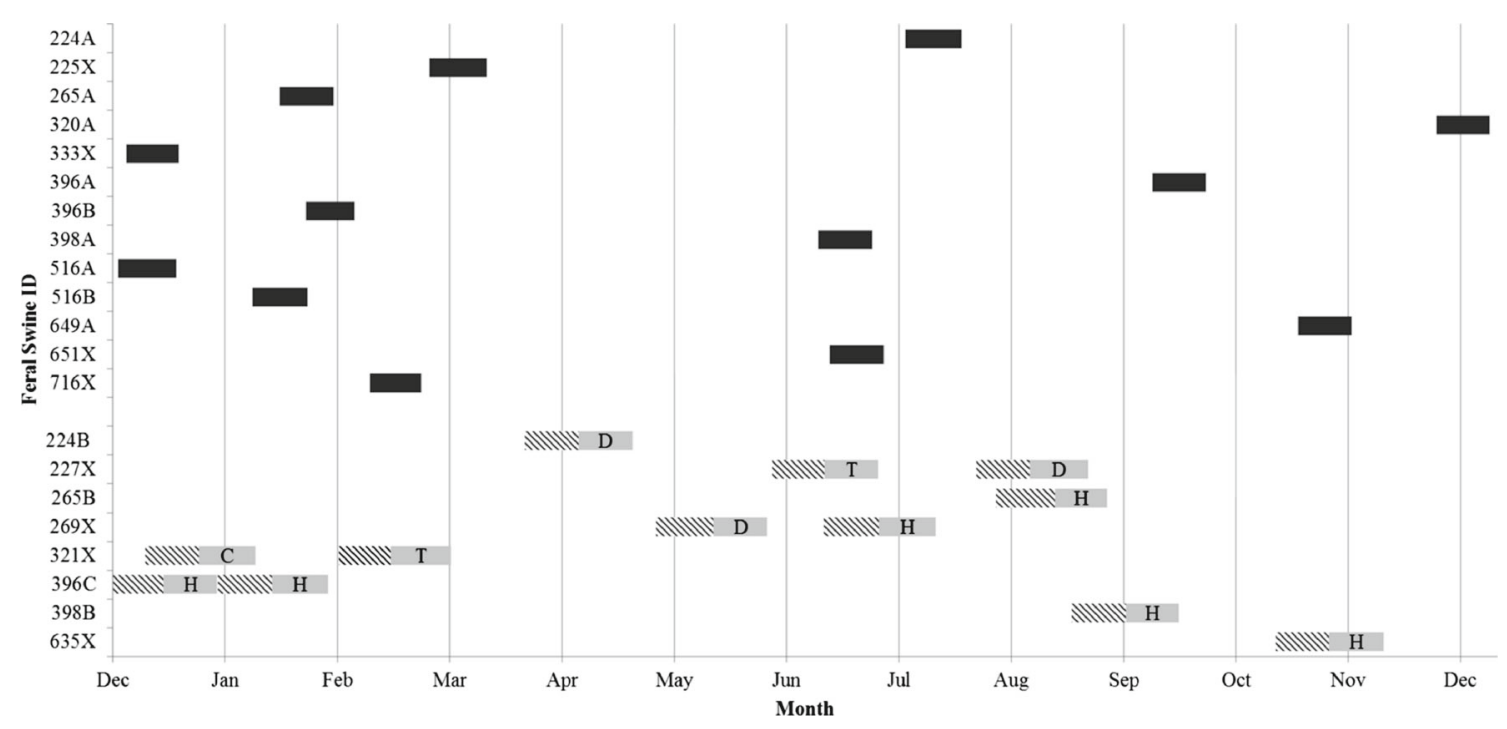

$\mathrm{C}=$ chased with helicoptor; $\mathrm{D}=$ chased with dogs; $\mathrm{H}=$ chased with hunter; $\mathrm{T}=$ trap-and-release

Fig. 1 Feral swine (Sus scrofa) control (dark grey boxes; 2-week periods) and treatment (diagonal hatching [2-week pre-removal period] and light grey [2-week post-removal period] boxes) GPS data periods summarized in one calendar year, used to measure effects of simulated removal activities on feral swine in southern MO, USA 
Table 1 Size of space-use areas (ha) and average daily movement distances (m) for 2-week pre- and post-removal periods for treatment feral swine and 2-week periods for control feral swine (Sus scrofa) in southern MO, USA

\begin{tabular}{|c|c|c|c|c|c|c|c|c|}
\hline \multirow[t]{2}{*}{ ID } & \multirow[t]{2}{*}{ Gender } & \multirow[t]{2}{*}{ Age } & \multicolumn{3}{|c|}{ Pre-simulated removal activity } & \multicolumn{3}{|c|}{ Post-simulated removal activity } \\
\hline & & & $50 \%$ (ha) & $95 \%$ (ha) & Movement (m) & $50 \%$ (ha) & $95 \%$ (ha) & Movement (m) \\
\hline \multicolumn{9}{|c|}{ First simulated removal activity } \\
\hline $265 \mathrm{~B}$ & $\mathrm{~F}$ & Adult & 42.48 & 151.68 & 2855.42 & 46.42 & 212.47 & 3383.34 \\
\hline $227 \mathrm{X}$ & $\mathrm{F}$ & Sub-adult & 31.82 & 189.33 & 2724.47 & 24.64 & 238.18 & 2439.97 \\
\hline $269 X$ & $\mathrm{~F}$ & Sub-adult & 78.14 & 506.34 & 2722.55 & 31.32 & 126.93 & 1073.99 \\
\hline $396 \mathrm{C}$ & M & Adult & 21.34 & 323.21 & 3320.92 & 17.88 & 176.83 & 2681.39 \\
\hline $398 \mathrm{~B}$ & M & Adult & 36.88 & 169.66 & 1685.29 & 30.64 & 160.28 & 2924.86 \\
\hline $321 X$ & M & Sub-adult & 13.15 & 93.15 & 1780.93 & 14.37 & 287.37 & 2983.68 \\
\hline \multirow[t]{2}{*}{$635 \mathrm{X}$} & M & Sub-adult & 131.30 & 800.92 & 3914.48 & 85.21 & 428.66 & 3139.32 \\
\hline & & Mean (SE) & $50.73(15.53)$ & $319.18(95.80)$ & $2714.86(299.15)$ & $35.78(9.14)$ & $232.96(38.23)$ & $2660.94(288.35)$ \\
\hline \multicolumn{9}{|c|}{ Second simulated removal activity } \\
\hline $224 B$ & $\mathrm{~F}$ & Adult & 20.51 & 94.12 & 2303.65 & 59.75 & 222.33 & 2907.32 \\
\hline $227 \mathrm{X}$ & $\mathrm{F}$ & Sub-adult & 32.21 & 131.81 & 2202.18 & 28.87 & 207.60 & 2689.07 \\
\hline $269 X$ & $\mathrm{~F}$ & Sub-adult & 22.96 & 116.15 & 1825.65 & 32.47 & 189.37 & 2240.82 \\
\hline $396 \mathrm{C}$ & M & Adult & 32.59 & 273.39 & 2873.89 & 60.24 & 327.04 & 4278.65 \\
\hline \multirow[t]{2}{*}{$321 X$} & M & Sub-adult & 96.10 & 415.97 & 3180.79 & 65.73 & 570.81 & 2800.32 \\
\hline & & Mean (SE) & $40.87(14.02)$ & $206.29(61.13)$ & $2477.23(243.18)$ & $49.41(7.75)$ & $303.43(71.00)$ & $2983.24(343.15)$ \\
\hline \multicolumn{9}{|l|}{ Control } \\
\hline $224 \mathrm{~A}$ & $\mathrm{~F}$ & Adult & 43.98 & 281.47 & 2498.63 & & & \\
\hline $333 X$ & $\mathrm{~F}$ & Adult & 75.98 & 298.90 & 3149.98 & & & \\
\hline $516 \mathrm{~A}$ & $\mathrm{~F}$ & Adult & 29.89 & 163.70 & 1460.34 & & & \\
\hline $516 \mathrm{~B}$ & $\mathrm{~F}$ & Adult & 33.47 & 401.70 & 3402.21 & & & \\
\hline $716 X$ & $\mathrm{~F}$ & Adult & 46.47 & 213.35 & 2059.06 & & & \\
\hline $225 X$ & $\mathrm{~F}$ & Sub-adult & 80.05 & 1681.15 & 3526.73 & & & \\
\hline $396 \mathrm{~B}$ & $\mathrm{~F}$ & Sub-adult & 27.58 & 265.44 & 1616.64 & & & \\
\hline $265 \mathrm{~A}$ & M & Adult & 93.94 & 544.85 & 2284.35 & & & \\
\hline $320 \mathrm{~A}$ & M & Adult & 51.91 & 311.48 & 3174.68 & & & \\
\hline $398 \mathrm{~A}$ & M & Adult & 64.82 & 341.79 & 3595.55 & & & \\
\hline $651 X$ & M & Adult & 42.64 & 197.51 & 1638.52 & & & \\
\hline $396 \mathrm{~A}$ & M & Sub-adult & 25.64 & 410.19 & 3568.03 & & & \\
\hline \multirow[t]{2}{*}{$649 \mathrm{~A}$} & M & Sub-adult & 59.37 & 455.17 & 3423.65 & & & \\
\hline & & Mean (SE) & $51.98(6.02)$ & $428.21(108.62)$ & $2722.95(228.40)$ & & & \\
\hline
\end{tabular}

\section{Discussion}

We observed little variation in feral swine movements and space use immediately following removal activities. Following the first removal activity, feral swine reduced their core UD areas while maintaining similar overall UD areas and daily movement distances. This reduction in core UD areas may be associated with an avoidance behavior and spending more time in hiding cover from harassment of our removal activities, similar to the response found by Keuling et al. (2008). Additionally, centroid shifts did not differ between the first and second removal activities and all but one individual moved its center of activity $<1 \mathrm{~km}$ after any removal activity. Conversely, following the second removal activity, feral swine increased their overall UD areas as well as increased diurnal movement distances. These results may be indicative of treatment individuals abandoning their established UD to avoid harassment. Sodeikat and Pohlmeyer (2003) observed similar results when wild boar were harassed by drive hunts; $40 \%$ of boar groups moved away from their core areas and relocated up to $6 \mathrm{~km}$, although these wild boars did return after 4-6 weeks.

Ideally, our study would have followed the same individuals beyond just two removal activities. Keeping harnessed feral swine alive and harnesses in good operating condition proved challenging. We did have one feral swine that received 


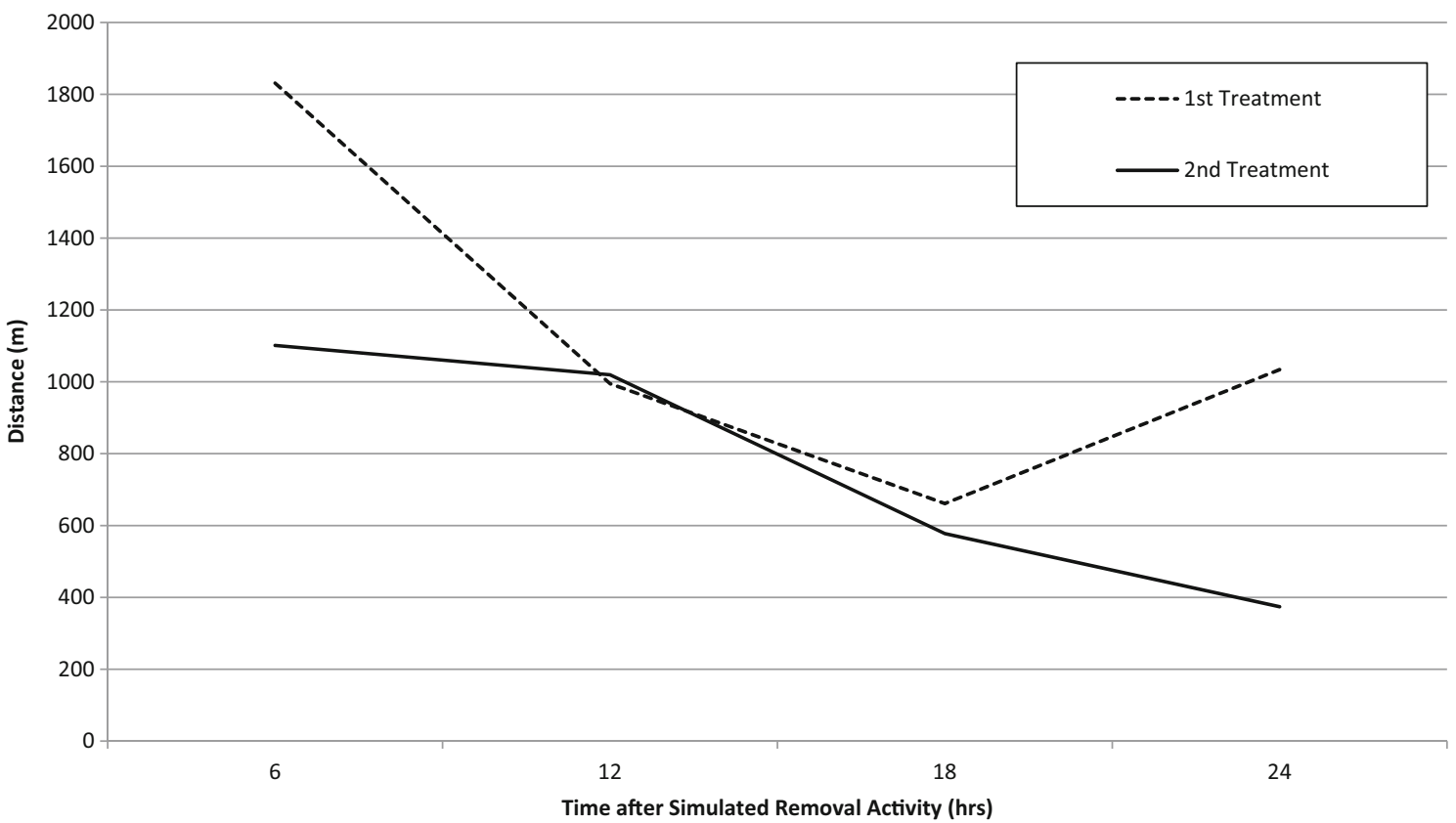

Fig. 2 Average distances (m) traveled by feral swine (Sus scrofa) in southern MO, USA, during the first $24 \mathrm{~h}$ directly after a simulated removal activity. The data are divided into four 6-h periods

four removal activities, however, with core and overall UD areas increasing after each removal activity, as well as increased distance between centroids and daily movement distances. Although highly speculative, we believe that this trend might continue as repeated removal activities are applied to the same individuals. These increased movements and

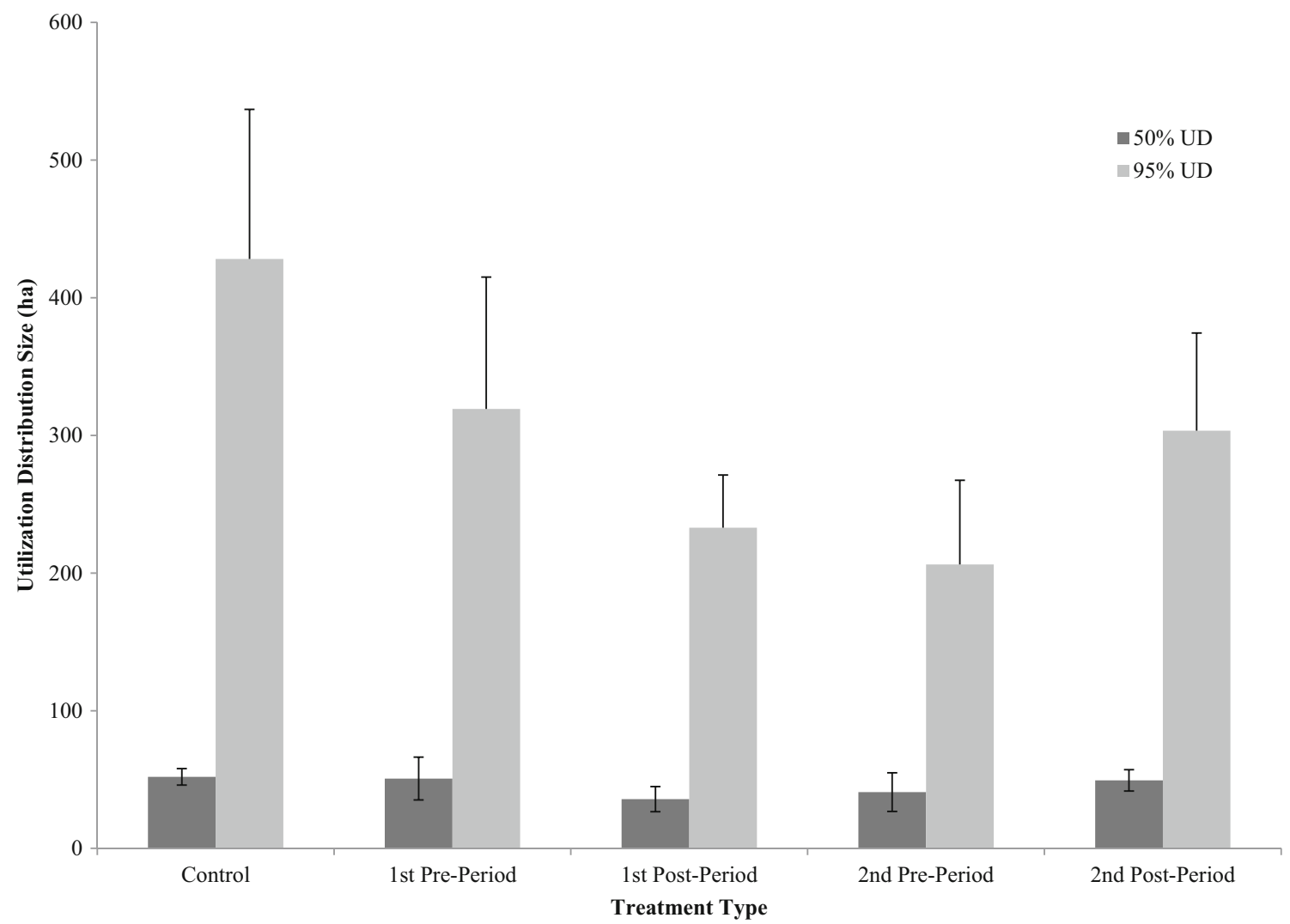

Fig. 3 Average size (ha; \pm SE bars) of 50 and $95 \%$ space-use areas (UDs) occupied by control and treatment feral swine (Sus scrofa) in southern MO, USA, for 2-week pre- and post-removal periods 
enlarged UD areas could result in increasing range expansion and risk of disease transmission (Giurgiutiu et al. 2009; Meng et al. 2009; Jay-Russell et al. 2014).

There is a general lack of knowledge surrounding effects of removal activities on feral swine in the USA and to a greater extent, North America. Campbell et al. (2010) found that feral swine core and home range sizes did not differ before and after aerial gunning in Texas; however, movement rates increased during the gunning phase. Although this removal activity was only applied once to collared feral swine, these findings support our first removal activity results. Similarly, population-wide culling activities, including trapping, controlled shooting, drive shooting, and aerial gunning that incorporated a centralized bait station, had no effect on size of areas used by feral swine, but movement rates at bait stations were greater compared to control sites (Campbell et al. 2012).

We were unable to adequately test the effect of different types of removal activities on feral swine; however, wildlife managers tasked with removing feral swine are also keenly interested in short- and long-term behavioral effects of removal activities (Maillard and Fournier 1995; Sodeikat and Pohlmeyer 2003; Scillitani et al. 2010). A negative consequence of removal activities is that feral swine quickly become more elusive after initial removal activities are applied (Diong 1980; Dexter 1996; Scillitani et al. 2010). Hunters with dogs in Australia repeatedly passed within $100 \mathrm{~m}$ of feral swine on numerous occasions during 5-day trails, because feral swine remained stationary and hidden (McIlroy and Saillard 1989). Another study from Australia noted that feral swine modified behaviors to avoid detection by helicopters during aerial shooting exercises (Saunders and Bryant 1988).

Initial activities aimed at removing feral swine from the landscape appear to have the least impact on behavior of surviving individuals. Continued disturbance or harassment could flush feral swine from their established use areas; thus, removal activities require innovative designs or techniques to maximize success. Future research would benefit from methods of feral swine removal that minimize human presence or harassment in a single effort because repeated harassment causes feral swine to increase movements and seek out refugia until the harassment has abated. Stealth sharpshooting and toxicants may be viable methods that would prevent continued disturbance of feral swine populations, but this requires future research.

Acknowledgments We thank the many coworkers and volunteers who assisted with the project design and data collection, especially C. Arias, J. Blair, and other staff from the Missouri Department of Conservation. Research was funded in part by the Missouri Department of
Conservation, USDA/APHIS/Wildlife Services (MO), and the National Wildlife Research Center.

\section{Compliance with ethical standards}

Ethical approval Study procedures were approved by a review board of Missouri Department of Conservation staff.

Conflict of interest The authors declare that they have no competing interests.

\section{References}

Anderson SJ, Stone CP (1993) Snaring to control feral pigs Sus scrofa in a remote Hawaiian rain forest. Biol Conserv 63:195-201

Barrett RH, Stone CP (1993) Hunting as a control method for wild pigs in Hawaii Volcanoes National Park: a report for resource management. Hawaii Volcanoes National Park Service, US Department of the Interior, HI, USA

Bates D, Maechler M, Bolker B, Walker S (2014) lme4: linear mixedeffects models using Eigen and S4. R package version 1.1-7. http:// CRAN.R-project.org $/$ package $=1 \mathrm{me} 4$

Benhamou S (2011) Dynamic approach to space and habitat use based on biased random bridges. PLoS One 6:e14592

Benhamou S, Cornelis D (2010) Incorporating movement behavior and barriers to improve kernel home range space use estimates. J Wildlife Manag 74:1353-1360

Bieber C, Ruf T (2005) Population dynamics in wild boar Sus scrofa: ecology, elasticity of growth rate and implications for the management of pulsed resource consumers. J Appl Ecol 42:1203-1213

Calenge C (2006) The package adehabitat for the R software: a tool for the analysis of space and habitat use by animals. Ecol Model 197: 516-519

Campbell TA, Long DB, Leland BR (2010) Feral swine behavior relative to aerial gunning in southern Texas. J Wildlife Manag 74:337-341

Campbell TA, Long DB, Lavelle MJ, Leland BR, Blankenship TL, VerCauteren KC (2012) Impact of baiting on feral swine behavior in the presence of culling activities. Prev Vet Med 104:249-257

Chambers M (1999) Conserving a resource. In: Coats M (ed) Proceedings of the first national feral swine conference. Texas Animal Health Commission, Austin, pp 115-116

Choquenot D, Kilgour RJ, Lukins BL (1993) An evaluation of feral pig trapping. Wildl Res 20:15-22

Choquenot D, Hone J, Saunders G (1999) Using aspects of predator-prey theory to evaluate helicopter shooting for feral pig control. Wildl Res 26:251-261

Coblentz BE, Baber DW (1987) Biology and control of feral pigs on Isla Santiago, Galapagos, Ecuador. J Appl Ecol 24:403-418

Development Core Team R (2013) R: a language and environment for statistical computing. The R Foundation for Statistical Computing, Vienna

Dexter N (1996) The effect of an intensive shooting exercise from a helicopter on the behavior of surviving feral hogs. Wildl Res 23: 435-441

Dickson JG, Mayer JJ, Dickson JD (2003) Wild hogs. In: Dickson JG (ed) Wildlife of southern forests: habitat and management. Hancock House Publishers, Blaine, pp 191-208

Diong CH (1980) Responses of feral pigs to trap types and food baits. In: Smith CW (ed) Proceedings of the Third Conference in Natural Sciences Hawaii Volcanoes National Park. University of Hawaii at Manoa, Honolulu, pp 91-100 
ESRI (2013) Environmental Systems Research Institute. Redlands, CA, USA

Giurgiutiu D, Banis C, Hunt E, Mincer J, Nicolardi C, Weltman A, Stanek D, Mathews S, Siegenthaler C, Blackmore C, Tiller R, De B, Stauffer K (2009) Brucella suis infection associated with feral swine hunting — three states, 2007-2008. Morb Mortal Wkly Rep 58:618621

Hess SC, Jeffrey JJ, Ball DL, Babich L (2006) Efficacy of feral pig removals at Hakalau Forest National Wildlife Refuge, Hawaii. Trans West Section Wildl 42:53-67

Hoffman DM (2009) Efficacy of shooting as a control method for feral hogs. In: Mayer JJ, Brisbin IL Jr. (ed) Wild pigs: biology, damage, control techniques and management. Savannah River National Laboratory SRNL-RP-2009-00869, Aiken, SC, USA, pp 289-291

Hone J (1983) A short-term evaluation of feral pig eradication in Willandra in Western New South Wales. Aust Wildl Res 10:269 275

Jay-Russell MT, Hake AF, Rivadeneira P, Virchow DR, Bergman DL (2014) Enteric human pathogens of wild boar, feral swine, and javelin (order: Artiodactyla). Proc $26^{\text {th }}$ Vertebr Pest Conf 26:291-295

Katahira LK, Finnegan P, Stone CP (1993) Feral pigs in montane mesic habitat at Hawaii Volcanoes National Park. Wildl Soc B 21:269-274

Keuling O, Stier N, Roth M (2008) How does hunting influence activity and spatial usage in wild boar Sus scrofa L.? Eur J Wildl Res 54: 729-737

Keuling O, Baubet E, Duscher A, Ebert C, Fischer C, Monaco A, Podgórski T, Prevot C, Ronnenberg K, Sodeikat G, Stier N, Thurfjell H (2013) Mortality rates of wild boar Sus scrofa L. in central Europe. Eur J Wildl Res 59:805-814

Kreith M (2007) Wild pigs in California: the issues. Agricultural Issues Center Brief No. 33, Davis, CA, USA.

Maillard D, Fournier P (1995) Effects of shooting with hounds on size of resting range of wild boar (Sus scrofa L.) groups in Mediterranean habitat. IBEX J Mt Ecol 3:102-107

Massei G, Roy S, Bunting R (2011) Too many hogs? A review of methods to mitigate impact by wild boar and feral hogs. Hum Wildl Interactions 5:79-99

Massei G, Kindberg J, Licoppe A, Gacic D, Sprem N, Kamler J, Baubet E, Hohmann U, Monaco A, Ozolins J, Cellina S, Podgorski T, Fonseca C, Markov N, Pokorny B, Rosell C, Nahlik A (2015) Wild boar population up, number of hunters down? A review of trends and implications for Europe. Pest Manag Sci 71:492-500

Mayer JJ (2009) Overview of wild pig damage. In: Mayer JJ, Brisbin IL Jr., (ed) Wild pigs: biology, damage, control techniques and management. Savannah River National Laboratory SRNL-RP-200900869, Aiken, SC, USA, pp 221-246
McCann BE, Garcelon DK (2008) Eradication of feral hogs from Pinnacles National Monument. J Wildl Manag 72:1287-1295

McIlroy JC, Gifford EJ (1997) The 'Judas' pig technique: a method that could enhance control programmes against feral hogs, Sus scrofa. Wildl Res 24:483-491

McIlroy JC, Saillard RJ (1989) The effect of hunting with dogs on the numbers and movements of feral pigs, Sus scrofa, and the subsequent success of poisoning exercises in Namadgi National Park, A.C.T. Aust Wildl Res 16:353-363

Meng XJ, Lindsay DS, Sriranganathan N (2009) Wild boars as sources for infectious diseases in livestock and humans. Philos Trans R Soc B 364:2697-2707

Parkes JP, Ramsey DS, Macdonald N, Walker K, McKnight S, Cohen BS, Morrison SA (2010) Rapid eradication of feral pigs (Sus scrofa) from Santa Cruz Island, California. Biol Conserv 143:634-641

Pimentel D (2007) Environmental and economic costs of vertebrate species invasions into the United States. In: Witmer GW, Pitt WC, Fagerstone KA (eds) Managing vertebrate invasive species: proceedings of an international symposium. USDA/APHIS/WS/ National Wildlife Research Center, Fort Collins, pp 2-8

Saunders G, Bryant H (1988) The evaluation of feral pig eradication program during simulated exotic disease outbreak. Aust Wildl Res 15:73-81

Scillitani L, Monaco A, Toso S (2010) Do intensive drive hunts affect wild boar (Sus scrofa) spatial behavior in Italy? Some evidences and management implications. Eur J Wildl Res 56: $307-318$

Seward N, VerCauteren K, Witmer G, Engeman R (2004) Feral swine impacts on agriculture and the environment. Sheep Goat Res J 19: 34-40

Shapiro L, Eason C, Bunt C, Hix S, Aylett P, MacMorran D (2015) Efficacy of encapsulated sodium nitrite as a new tool for feral pig management. J Pest Sci 1-7

Sodeikat G, Pohlmeyer K (2003) Escape movements of family groups of wild boar Sus scrofa influenced by drive hunts in Lower Saxony, Germany. Wildl Biol 9:43-49

Toigo C, Servanty S, Gaillard JM, Brandt S, Baubet E (2008) Disentangling natural from hunting mortality in an intensively hunted wild boar population. J Wildl Manag 72:1532-1539

West BC, Cooper AL, Armstrong JB (2009) Managing wild pigs: a technical guide. Hum Wildl Interactions Monogr 1:1-55

Witmer GW, Sanders RB, Taft AC (2003) Feral swine - are they a disease threat to livestock in the United States? Proc Wildl Damage Manag Conf 10:316-325

Zivin J, Hueth BM, Zilberman D (2000) Managing a multiple-use resource: the case of feral pig management in California rangeland. J Environ Econ Manag 39:189-204 